\title{
On the optical transmission properties of Pentelic and Paros marble
}

\author{
Rosa Weigand, ${ }^{1, *}$ Pablo A. García, ${ }^{2}$ Joaquín Campos Acosta, ${ }^{3}$ and Jacobo Storch de \\ Gracia ${ }^{4}$ \\ ${ }^{1}$ Departamento de Óptica, Facultad de Ciencias Físicas, Universidad Complutense de Madrid, Avda. Complutense s/n, \\ Ciudad Universitaria, 28040 Madrid, Spain \\ ${ }^{2}$ Instituto de Lenguas y Culturas del Mediterráneo y Oriente Próximo, Centro de Ciencias Humanas y Sociales, Consejo \\ Superior de Investigaciones Científicas (CSIC), C/ Albasanz 26-28, 28037 Madrid, Spain \\ ${ }^{3}$ Instituto de Óptica, Consejo Superior de Investigaciones Científicas (CSIC), Serrano 144, 28006 Madrid, Spain \\ ${ }^{4}$ Departamento de Ciencias y Técnicas Historiográficas y de Arqueología, Facultad de Geografía e Historia, Edificio B, \\ Universidad Complutense de Madrid, C/ Profesor Aranguren s/n, Ciudad Universitaria, 28040 Madrid, Spain \\ ${ }^{*}$ Corresponding author: weigand@fis.ucm.es
}

Received 11 September, 2014; revised December 5, 2014; accepted

December 5, 2014; posted December 9, 2014 (Doc. ID 222601); published

January 27, 2015

\begin{abstract}
The ancient greek and roman sources report that the statue of Zeus in Olympia had a head, and specially the eyes, similar to the description of Zeus by Homer, so we think that the statue was visible to human eye. Since the temple was 12 meter high, had a small door and no windows,_the illumination of the statue by conventional media is questionable. The aim of this paper is to characterize the optical transmission of Paros and Pentelic marble to demonstrate that it was possible to have the Zeus temple illuminated through the roof marble tiles. Spectral absolute transmittance measurements were taken in samples with different thicknesses using a calibrated spectrophotometer, as well as total transmittance measurements using a luxmeter. The results show that both types of marble transmit light and Pentelic marble has a higher transmittance in the visible range than Paros marble in some cases and hence could have been one reason, among others, to change the type of marble in the roof in the antiquity. (C) 2014 Optical Society of America

OCIS codes: (330.7325) Visual Optics, Metrology; (160.4760) Materials: Optical Properties.

http://dx.doi/org/10.1364/AO.99.099999
\end{abstract}

\section{Introduction}

Pausanias was an ancient Greek traveler who lived in the II

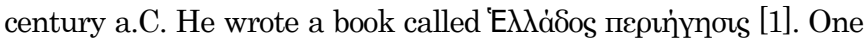
well known chapter of the Pausanias work was the fifth one about his trip to Elis, where he described the Zeus temple in Olympia. He portrayed one of the most famous buildings in the ancient world. Unfortunately, Pausanias report is the only one, with a little paragraph of Strabo work, Geographica, which describes the place and the sculpture included inside.

The figure of Zeus housed in the temple was one of the seven wonders of the ancient world on Antipater's list, and the own temple became the canon of the Doric order. According to the Pausanias' and Strabo's [2] description the building was erected between 470 b.C. and 456 b.C., being Libon of Elis the architect. According to the belief of many authors, the sculpture included inside was not developed until 432 b.C., 24 years later. It was a chryselephantine sculpture (ivory and gold) that measured about twelve meters high and was sculpted by Pheidias, the most famous sculptor in ancient Greece. Ancient sources like Strabo [2] describe the gaze of God, referring to some verses of Homer: "The son of Cronos spoke, and bowed his dark brow in assent, and the ambrosial locks waved from the king's immortal head; and he made great Olympus quake." This description hints for the fact that the head could be seen, even if it was near the roof and was 12 meters high.

For several centuries Olympia was a political, religious and sports meeting point, until Theodosius I (Theodosius the Great) Government, who banned every pagan ritual. A few years later Theodosius II (Theodosius the Younger) promulgated the Theodosian law code. This code not only forbid the pagan rituals, but ordered to destroy every religious place that would not have been converted to the Christian religion [3]. The human hand and a pair of earthquakes condemned the Greek sanctuary to oblivion. The Zeus sculpture was saved by Lausus (The imperial chamberlain of Theodosius II). It was hosed in the Constantinople Lausus' palace along with Praxiteles' Aphrodite of Knidos, Hera of Samos or the Athena of Lindos. In 475 a.C., Constantinople suffered a fire and the Palace's was destroyed. From this moment up to the XVIIth century a.C., when the first travelers rediscovered the Greek Olympian sanctuary, one of the most beautiful ancient world art work, it was just a memory in old books. 
The temple was the canon of the Doric order, its measures were 27.68 meters wide by 64.12 meters long, and every column was 10.48 meters high [4]. The ancient sources wrote that the Zeus sculpture inside the temple was 12 meters high and was close to the roof. Also, the sources said that the whole temple was made in local stone, but the roof. The roof was made of marble. Fragments of both Paros and Pentelic marble flat tiles have been found $[4,5]$. However we ignore whether they coexisted or the roof was totally replaced. In any case, Pausanias in his description of the temple assures that the marble was from mount Pentelic, in the greek continent [1]. Marble Paros is extracted from the island of Paros, close to the turkish coast. Let us add to this that the Athenian Parthenon is contemporary of the Temple of Zeus. Phydias was the author of the Zeus sculpture and the director of the Parthenon construction. Since the roof of the Parthenon was made of Paros marble, we find it feasible that the same Paros marble was used for the temple of Olympia and later was changed to Pentelic marble, the one that Pausanias observed. Moreover, since mount Pentelic was much closer to the temple than the island of Paros, its use was economically much more favorable. Reasons for the change of Paros to Pentelic marble could have been earthquakes [6] or the restructuring that the temple underwent when the statue was introduced $[4,6]$.

The rests of the tiles found in the Temple of Zeus have got 2.8 $\mathrm{cm}$ to $3 \mathrm{~cm}$ thickness. They couldn't be thinner while maintaining the area, because they would break. Motivated by the fact that marble is translucent and by the historical descriptions of Pausanias, we want to show that there could have been a technical reason for the Romans to change the roof of the temple of Zeus from Paros to Pentelic marble due to its better optical transmission in the visible zone of the spectrum [7].

\section{Experimental}

The samples tested in this work consisted of Paros marble with $1 \mathrm{~cm}, 2 \mathrm{~cm}$ and $2.8 \mathrm{~cm}$ thickness (samples identified as Pa1, $\mathrm{Pa}$, Pa2.8, respectively) and Pentelic marble with $1 \mathrm{~cm}, 1.5 \mathrm{~cm}$, $2 \mathrm{~cm}$ and $3 \mathrm{~cm}$ thickness (samples identified as Pe1, Pe1.5, Pe2, Pe3, respectively).

These samples were fabricated departing from Paros and Pentelic stones collected in Greece, manually cut to have two flat parallel faces with a wet saw and also manually polished with fine grain corundum emery to reproduce the surface quality that ancient marble tiles should have had. Depending on the original size of the stone the flat surface was larger or smaller, being the smallest one around $2 \times 3 \mathrm{~cm}^{2}$. In his book [1], Pausanias mentions that Evergo from Naxos was contracted to fabricate the tiles.

Due to different material composition, grain structure and surface finishing, different absorption and scattering losses are to be expected in the different samples.

To measure the total visual transmittance of the different samples and to have a measurement of the amount of visible light that could have been seen inside the temple for a person to observe the statue, we used the Sun as light source and a digital luxmeter as detector. The setup can be seen in Figure 1. The luxmeter Model ISO-TECH ILM350 was directed towards the sun on a cloud-free day (Madrid, Spain, March 2014, 3 pm) and illuminance measurements without and with the marble samples were done. Care was taken to use an added infrared filter to avoid measuring infrared radiation, just in case the luxmeter is not well corrected for the IR, and to use an iris for the luxmeter with the area of the smallest sample. The uncertainty of this luxmeter model is in the order of $10 \%$, according to the manufacturer's specification. It has not been calibrated with the IR filter on it and its parameter $\mathrm{f}_{1}$ ' is unknown, although a low value (high quality) is not expected, since it has a selenium cell. Hence, the visual term in this work is only approximate.

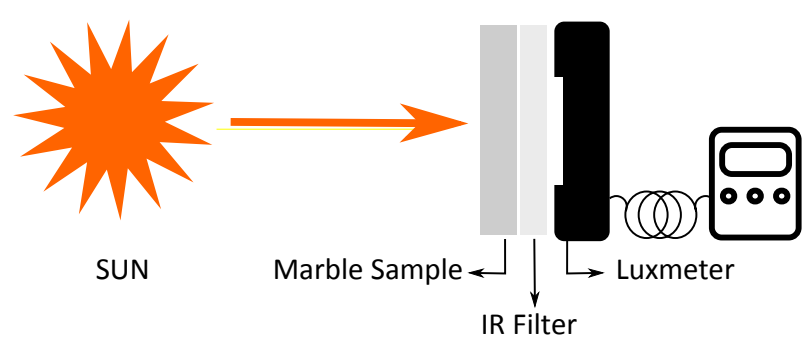

Fig. 1. (color online only) Experimental setup for the measurement of illuminance.

Table 1 shows the illuminance reading given by the luxmeter plus the IR filter to the sunlight and the reading to the sunlight transmitted by the different marble pieces when the were put over, for measurement.

It can be observed that although the percentage of light that comes through the samples is low, the luminance of the roof from inside would be over $5 \mathrm{~cd} / \mathrm{m}^{2}$ for all samples during most part of the day.

Table 1. Illuminance readings / lux

\begin{tabular}{cccc}
\hline Sample & $\begin{array}{c}\text { Sun } \\
\text { Light }\end{array}$ & $\begin{array}{c}\text { Transmitted } \\
\text { Light }\end{array}$ & Percentage (\%) \\
\hline Pa1 & 7600 & 200 & 2.6 \\
Pa2 & 7600 & 122 & 1.6 \\
Pa2.8 & 7200 & 30 & 0.42 \\
Pe1 & 8500 & 120 & 1.41 \\
Pe1.5 & 8600 & 130 & 1.51 \\
Pe2 & 8900 & 60 & 0.67 \\
Pe3 & 8500 & 34 & 0.4
\end{tabular}

An estimate of the luminance can be calculated by multiplying a typical solar illuminance $(100.000 \mathrm{~lx})$ by the percentage transmitted and by dividing the result by $2 \pi$ (assuming a lambertian performance for the marble), which the authors considered to be a good enough approximation for the purpose of this work. That means that the roof's luminance would clearly be in the photopic range $(5 \mathrm{~cd} / \mathrm{m} 2$ is usually accepted as the lower limit for photopic vision $[8,9])$ and would produce a high enough illuminance over the Zeus statue to draw the attention of the visitor entering the temple, particularly in a dim enclosure as the temple seemed to be, and to allow distinguishing colors on it.

It is also observable that although the Paros samples have in general a higher transmittance than Pentelic samples for similar thicknesses, Pentelic marble transmits as much as Paros one for the largest thickness measured in this work. It seems that the 
transmittance gradient with thickness is greater for Paros than for Pentelic marble.

More precise information can be extracted from spectral transmittance measurements. For this purpose we used a calibrated spectrophotometer Perkin Elmer Lambda 900 equipped with an integrating sphere to collect all the light transmitted by the sample, so that absolute spectral total transmittance measurements could be taken. Figures 2 and 3 show the spectral transmittance for the two types of marble and different thicknesses, irradiating an area of $2 \times 1 \mathrm{~cm}^{2}$.

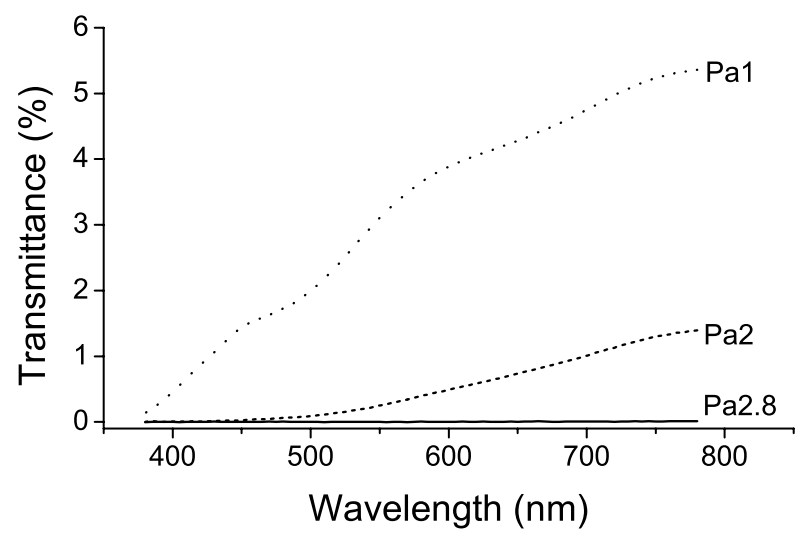

Fig. 2. Spectral total transmittance measurements for Paros marble, samples Pa1, Pa2 and Pa2.8.

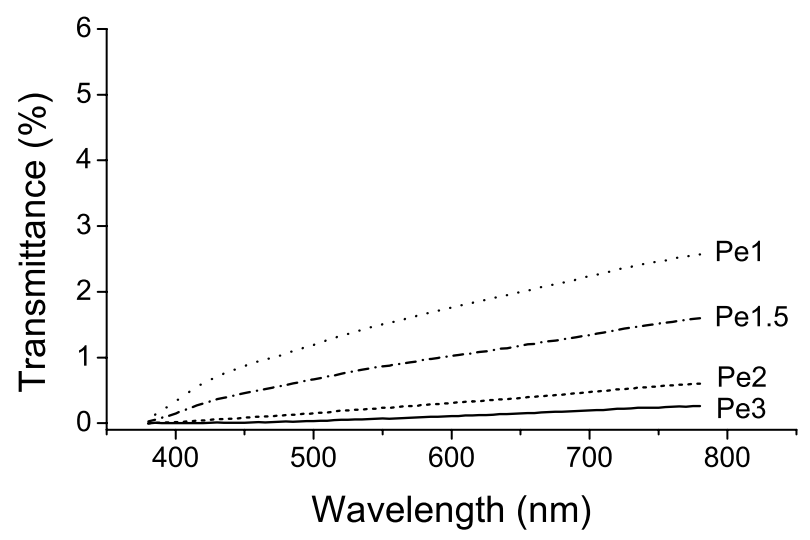

Fig. 3. Spectral total transmittance measurements for Pentelic marble samples Pe1, Pe1.5, Pe2, and Pa3.

Spectral transmittance measurements show that the values given in table I are good enough to derive the conclusion about the radiance of the roof. Furthermore, both Figures 2 and 3 show that the samples transmit more light in the red-yellow zone of the spectrum than in the green-blue. This is an interesting fact since the statue was made of ivory and gold, so red-yellowish light is more appropriate for its illumination. It can also be observed that, although Paros marble has got a higher transmittance than Pentelic marble for thicknesses up to $2 \mathrm{~cm}$, it doesn't transmit that much for the $2.8 \mathrm{~cm}$ thickness, while Pentelic marble with $3 \mathrm{~cm}$ thickness does. In principle this is not a standard behavior, so we decided to measure the hemispherical reflectance of the samples to be able to estimate their absorption. 0:d reflectance was measured in the same Lambda 900 spectrophotometer with an integrating sphere attachment. Since the uniformity of the samples' surface is not high because of the nature of the marble itself, we measured the reflectance at different positions, illuminating an area of $1 \mathrm{~cm}$ by $2 \mathrm{~cm}$. Since the polished surface is not wide enough for some samples, different positions were obtained by rotating the sample around an axis normal to its surface. The average spectral results of the different positions and different thickness for every material are shown in Figure 4. The variance between measurements of the same sample is equivalent to the variance of samples of the same material with different thickness and is in the order of $5 \%$.

It can be observed that Pentelic samples reflect more light than Paros ones. Furthermore, Pentelic is spectrally more neutral than Paros.

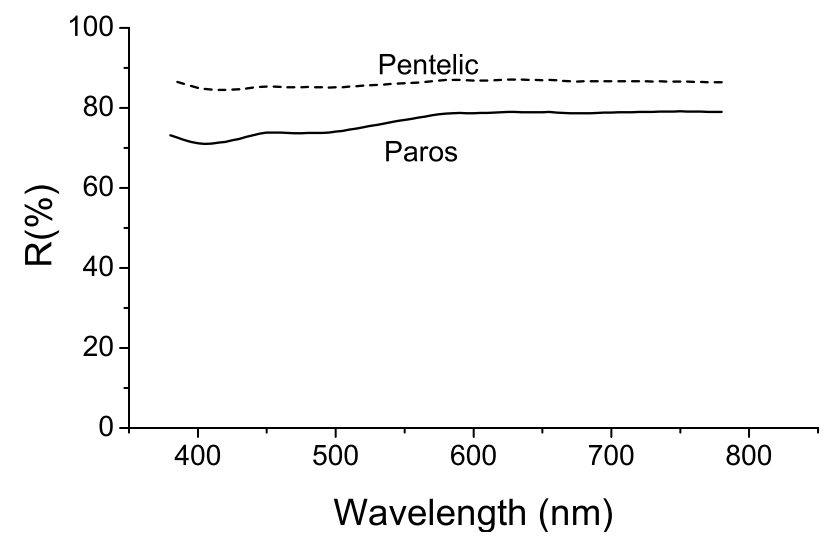

Fig. 4. Average reflectivity for Paros and Pentelic samples.

In order to asses the behavior in more detail, we have deduced the extinction coefficients of the marbles. The main processes that control the losses of light when propagating through the samples are absorption (due to the chemical composition of the marble) and scattering (due to the granulated structure of the samples). If we define $\alpha_{a}$ as the absorption coefficient and $\alpha_{\mathrm{s}}$ as the scattering coefficient, the light transmitted by a sample of thickness $L$ is given according to a Lambert-Beer law by

$$
\begin{aligned}
& I_{t}=(1-\rho) I_{0} e^{-\alpha_{a} L} e^{-\alpha_{s} L}=(1-\rho) I_{0} e^{-\left(\alpha_{a}+\alpha_{s}\right) L}= \\
& =(1-\rho) I_{0} e^{-\alpha L}
\end{aligned}
$$

where $\rho$ is the surface reflectance. Spectral dependencies have been omitted for simplicity. So the total extinction coefficient $\alpha$ is given by

$$
\alpha=\alpha_{\mathrm{a}}+\alpha_{\mathrm{S}}
$$

and can be deduced from the transmittance measurements by using

$$
\alpha=-\frac{\ln (\tau / 100)-\ln (1-\rho)}{L}
$$


since the direct transmittance measurement of the spectrometer is $\tau=\left(\mathrm{I}_{t} / \mathrm{I}_{0}\right) \times 100$.

If all the Paros samples had the same chemical composition and the same grain structure and the same surface finish, we would obtain the same extinction coefficient $\alpha$ for all of them. The same would apply for Pentelic samples, and we could have two extinction coefficients to compare with each other. However when applying eq. (3) to the different samples of each material, the results of Figs. 5 and 6 are obtained for the extinction coefficient.

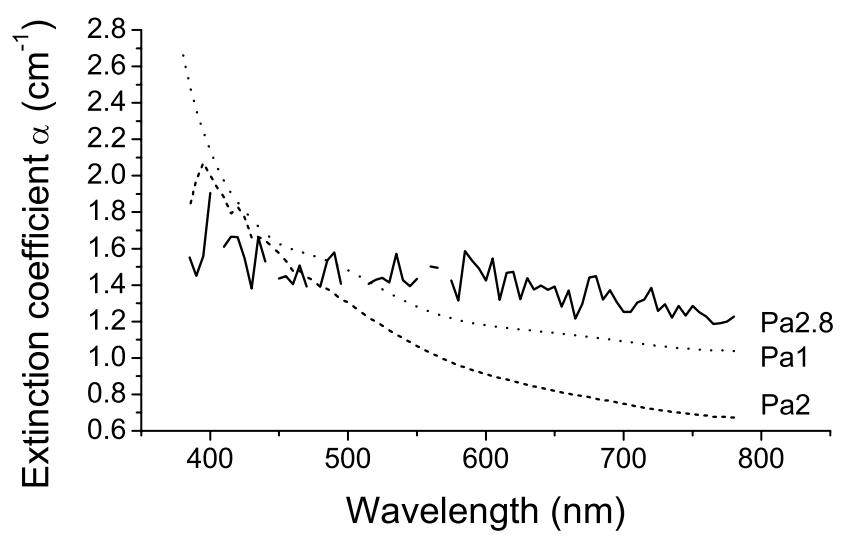

Fig. 5. Extinction coefficient $\alpha$ plus a constant for the different Paros marble samples $\mathrm{Pa} 1, \mathrm{~Pa} 2$, and $\mathrm{Pa} 2.8$.

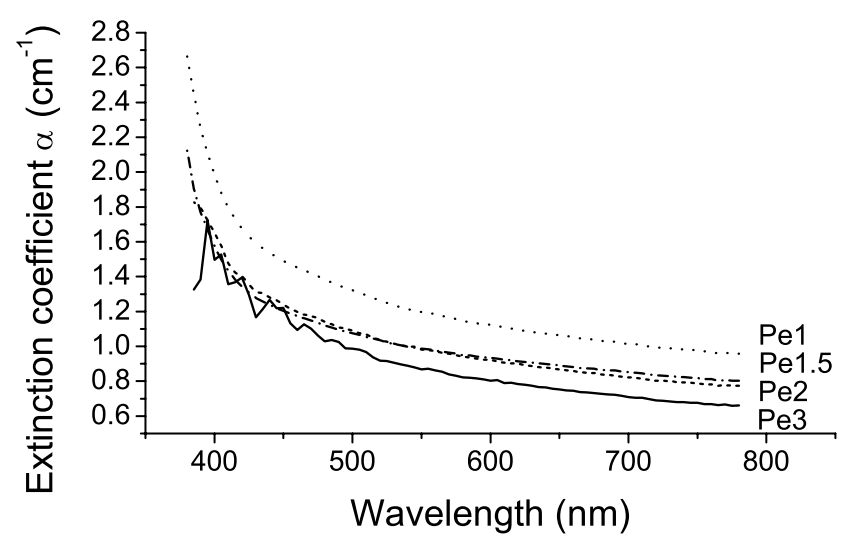

Fig. 6. Extinction coefficient $\alpha$ plus a constant for the different Pentelic marble samples Pe1, Pe1.5, Pe2, and Pa3.

It is apparent that different total extinction coefficients spectral distributions are obtained even for the same type of marble. It is also apparent that data are noisier for the thickest samples of both materials. This is because the reflectance measurements, as well as the transmittance measurements, are much noisier, particularly for the thick Paros sample. However, the spectral feature is kept close, particularly in the case of Pentelic. In the case of Paros samples, the thickest one has got a more differentiated spectrum. This might be because the measurement is very uncertain: the spectral transmittance of this sample is very low, so the result is affected by a high uncertainty, more than $10 \%$ and the reflectance variance is high because of the surface non uniformity (stripes were visible on it). In addition, the thickness of the sample cannot be accurately determined and may change across the reference surface. This problem is common to the other samples too. Take into account that these samples were taken from the ground in the region, without a special selection and then they were manually polished.

Therefore these results indicate his indicates that, either chemical composition, or the grain structure, or the surface finish of the different marble samples varies in a smaller or larger extent. It is also apparent that the scattering processes play a major role, since the higher extinction coefficients are in the bluegreen zone of the spectrum, where all types of scattering have larger losses, but also the optical properties of the constituent materials would contribute in the same way (absorption in the blue-UV zone). So the differences between different Paros samples and between different Pentelic samples could be attributed to their different grain structure, uniformity of its chemical composition and surface finish. No data are available to authors about the natural variability of these parameters in these types of marble.

\section{Conclusions}

We have spectrally characterized the optical transmission of Paros and Pentelic marble samples. The illuminance measurements performed with solar light revealed that the transmittance of the thickest marble samples $(2.8 \mathrm{~cm}$ and $3 \mathrm{~cm}$ respectively) was high enough for a human to perceive the statue when entering the temple of Zeus and this result has been confirmed by the spectrophotometric characterization. The spectral total transmittance measurements evidence a higher transmission in the yellow-red zone of the spectrum, which is adequate when illuminating an object made of ivory and gold. They also reveal different extinction coefficients between different samples of the same marble type, although the spectral feature is similar. The reason for this is not clear and can be due to high variance of the reflectance of the same sample and from sample to sample when varying the illuminated area, noisy measurements, etc... A strong contribution of the absorption and scattering processes on the losses experienced by the light propagating through the samples is also shown by the spectrophotometric data.

Finally we can point out that since for large thicknesses, our Pentelic marble has a higher transmittance than the Paros marble, this could have been a possible additional reason to exchange the marble type of the temple's roof from Paros to Pentelic during the Roman period, along with the economical reasons.

\section{References}

1. Pausaniae. Graeciae descriptio. Ed. María Helena RochaPereira, (Teubner, Leipzig 1989-1990).

2. Strabo. Géographie. Translated from the Greek by Germaine Aujac et François Lasserre. (Les Belles Lettres, Paris, 1966-1981).

3. Monsen, Theodor. Les lois religieuxes des empereurs romaines de Constantin a Theodose II. (Editions Du Cerf, Paris, 2005).

4. Mallwitz, Alfred. Olympia und seine Bauten. (Prestel Verlag, Munich, 1972). 
5. Frazer, James George. Graecia antiqua: maps and plans to illustrate Pausanias' description of Greece, (Macmillan and Co. London, 1930).

6. Hennemeyer, Arnd. Licht Konzepte. Pages 102-109 (Schnell und Steiner Verlag, Regensburg, 2011)

7. García Pastor, Pablo A. Una reconstrucción del templo de Zeus de Olimpia: hacia la resolución de los "Phidiasprobleme". PhD. Thesis, 2013.

(http://eprints.ucm.es/24019/)

8. Michael Bass Ed. Handbook of Optics. Vol. II. Devices, Measurements \& Properties. Chapter 24. (McGraw-Hill, 1995).

9. ILV: International Lighting Vocabulary, Standard CIE S 017/E:2011 (also accessible electronically at http://eilv.cie.co.at) 